\title{
Rapid Detection of Acute Respiratory Virus and Atypical Bacteria Infections in Children
}

\author{
Cai Xuan ${ }^{1, *}$, Li Yan ${ }^{1}$, Wu Zegang ${ }^{1}$ \\ ${ }^{1}$ Clinical Laboratory, Renmin Hospital of Wuhan University, Wuhan, China \\ *Corresponding author: Cai Xuan, Clinical Laboratory, Renmin Hospital of Wuhan University, Wuhan 430060, China. Email:, E-mail: cai_prof@yeah.net
}

Received: May 07, 2012; Revised: July 31, 2012; Accepted: August 08, 2012

\begin{abstract}
Background: Acute respiratory infection (ARI) is one of the primary diseases that cause high morbidity and mortality to children especially in developing countries. ARI can come from a number of pathogens, which are not necessarily identical in different regions or groups. As similar symptoms become evident in child ARI without specific particularities, respiratory infectious diseases are most of the time clinically diagnosed and treated less selectively than required, and antibiotics are largely used for non-bacterial respiratory system infections. Therefore, rapid detection of respiratory pathogens is necessary for the correct and appropriate treatment of ARI.

Objectives: To obtain a general understanding of the pathogenic spectrum of ARI for children and provide basis for clinical infection control and pathogenic detection.

Materials and Methods: Serum specimens from 4550 child victims with ARI symptoms were collected and detected for IgM antibodies of nine common pathogens using the indirect immunofluorescence assay (IFA).

Results: Of the 4550 child victims, 3660 were antibody positive (80.4\%), with detectable rates of $67.3 \%, 90.9 \%, 92.4 \%$ and $91.4 \%$ for the $\leq 1$, $1<\mathrm{y} \leq 3,3<\mathrm{y} \leq 6$ and $>6$ age groups respectively $(\mathrm{P}<0.05)$. Except for Coxiellaburneti (COX), the difference in the detectable rates of other pathogens between the groups was statistically significant. Of the nine pathogens, Mycoplasma pneumoniae (MP) had the highest detectable rate, followed by influenza B virus(FluB), respiratory syncytial virus(RSV), parainfluenza virus(PIV), adenovirus (ADV), influenza A virus (FluA), Legionella pneumophila sero group I(LPN-I), Coxiellaburneti (COX) and Chlamydia pneumoniae (CPn); and 718 suffered mixed infections (81.4\%), typically of two pathogens (MP+FLuB).

Conclusions: MP, FluB and RSV are the principal contributors to ARI in the Hubei area, with mixed infections, typically of MP and FluB, being the most common pathogens statistically significant between different age groups.
\end{abstract}

Keywords: Child; Respiratory Tract Infections; Pathogen; Coinfection

\section{Background}

Acute respiratory infection (ARI) is one of the primary diseases that cause high morbidity and mortality in children especially in developing countries. According to statistics, 19 million children in the world died of ARI in 2000 alone, of whom 70\% were from Africa and Southeast Asia (1). Of the causes of death for children under 5 years old between 2000 and 2003, ARI (including pneumonia) accounted for $19 \%$ (2), same as in 2008 , when ARI (including pneumonia) accounted for $18 \%$ of the causes of death for children under 5 years old, of whom children in Southeast Asia ranked first for deaths caused by acute respiratory infections at the proportion of $21 \%$, compared to those in America (12\%) (3). However, with no exception for either developing or developed countries, ARI embodies a heavy economic burden for both families and the society.

ARI can come from a number of pathogens, which are not necessarily identical in different regions or groups. However, ARI is generally caused by bacterial infection (4-6), with Streptococcus pneumoniae being the most common, while atypical bacteria (e.g. Mycoplasma pneumoniae) and viruses also take a considerably significant share. This is particularly evident in upper respiratory infections where M. pneumoniae and viruses have caused even more infections than bacteria. Besides, more viruses are being discovered such as human metapneumovirus

Implication for health policy/practice/research/medical education:

Acute respiratory infection (ARI) is one of the primary diseases that cause high morbidity and mortality to children especially in developing countries. As respiratory pathogen infections are potential causes of severe complications that threaten children's health, rapid detection of respiratory pathogens is very essential for the correct and appropriate treatment of respiratory infections as it enables timely treatment of the victims and prevents complications. So far, a lot of detection methods are available for acute respiratory infectious pathogens. Immunofluorescence assay, on the other side, is more acceptable for developing countries as it enables rapid detection of antibodies for its sensitive and specific properties and provides immediate etiological basis for clinical diagnosis at a much lower cost.

Copyright (C) 2013, Ahvaz Jundishapur University of Medical Sciences; Licensee Kowsar Ltd. This is an Open Access article distributed under the terms of the Creative Commons Attribution License (http://creativecommons.org/licenses/by/3.0), which permits unrestricted use, distribution, and reproduction in any medium, provided the original work is properly cited. 
and coronavirus (NL63 and HKU1) (7, 8). Furthermore, as many viruses feature high infection, quick transmission, short delitescence, immediate attack and absence of lifetime immunity after illness, which constitute a combined cause of high morbidity and mortality, a pandemic outbreak of diseases like influenza virus can be expected $(9,10)$. Also, as similar symptoms are evident in child ARI without specific particularities, respiratory infectious diseases are most of the time clinically diagnosed and treated less selectively than required, and antibiotics are used at large for non-bacterial respiratory system infections. Therefore, rapid detection of respiratory pathogens is necessary for the correct and appropriate treatment of ARI. This paper provides important information for clinical diagnosis and preparation of the exact treatment plan by detecting the IgM antibodies of nine pathogens in the serum of 4500 child ARI victims at the pediatrics department of People's Hospital of Wuhan University, Hubei Province from May 2010 to Apr 2011 using the indirect immunofluorescence assay (IFA).

\section{Objectives}

The aim of this study was to obtain a general understanding of the pathogenic spectrum of ARI for children and provide the basis for clinical infection control and pathogenic detection.

\section{Materials and Methods}

\subsection{Patient Information}

A total of 4550 child victims, aged between 1 month and 15 years and averaging 33 months, including 2872 males and 1678 females, at the pediatrics department of People's Hospital of Wuhan University from May 2010 to Apr 2010, with ARI symptoms like a running nose, sneezes, coughs, dizziness and generalized weakness were studied. As grouped by age: 2070 were up to and including 1 years old, 1384 were between 1 and 3 years, 697 between 3 and 6 years and 399 more than 6 years.

\subsection{Specimens and Detection Method}

Serum specimens were collected from qualified child victims of upper respiratory infections the next morning after admission. 3-4ml of venous blood was collected and immediately transferred to the clinical examination center of People's Hospital of Wuhan University, where serum was separated centrifugally from the coagulated blood at 3000rpm (any specimen not immediately detected was kept in a refrigerator and detected the next day, with specimen storage not exceeding 24 hours) and then detected by IFA (indirect immunofluorescence assay) for serum IgM antibodies for all the nine commonly seen upper respiratory infectious pathogens in serum, i.e. FluB, influenza B virus; MP, M. pneumoniae; RSV, respiratory syncytial virus; $\mathrm{ADV}$, adenovirus; $\mathrm{COX}$, Coxiellaburneti; CPn, Chlamydia pneumoniae; FluA, influenza A virus; LPN-I, Legionella pneumophila sero group I; PIV, parainfluenza virus. The operation instructions were followed during the procedure. The IgM antibody test kit (VIRCELL, Spain) and a German EUROStar II fluorescence microscope were used.

\subsection{Statistical Processing}

$\chi^{2}$ test was conducted for the infection difference between different age groups and $\mathrm{P}<0.05$ was consideredstatistically significant. All the data processing was made on the SPSS (Statistical Product and Service Solutions) 17.0 software.

\section{Results}

\subsection{Detectable Rate of Individual Pathogens}

Of the 4550 serum specimens, one or more pathogens were detected in 3660 cases, indicating a detectable rate of $80.4 \%$, with MP ranking the highest at 3084 (67.8\%), followed by FluB at 2192 (48.2\%), RSV at 1513 (33.3\%), PIV at 457 (10.0\%), ADV at 367 (8.1\%), FluA at 114 (2.5\%), LPN at 97 (2.1\%), COX at 28 (0.6\%) and CPn at $13(0.3 \%)$, as shown in Table 1. $\mathrm{MP}$, FluB and RSV are the main infectious pathogens.

\begin{tabular}{|c|c|c|c|c|c|c|c|c|c|c|}
\hline Pathogen & $\operatorname{ADV}^{a}$ & $\operatorname{cox}^{a}$ & $\mathrm{CPn}^{\mathrm{a}}$ & FluA $^{a}$ & FluB $^{\mathbf{a}}$ & LPN & $\mathrm{MP}^{\mathrm{a}}$ & PIV $^{\mathbf{a}}$ & $\operatorname{RSV}^{\mathrm{a}}$ & Total Infection \\
\hline Qtya & 367 & 28 & 13 & 114 & 2192 & 97 & 3085 & 457 & 1513 & 3660 \\
\hline Percentage & 8.1 & 0.6 & 0.3 & 2.5 & 48.2 & 2.1 & 67.8 & 10.0 & 33.3 & 80.4 \\
\hline
\end{tabular}

a Abbreviations: Qty, quantity; FluB, influenza B virus; MP, mycoplasma pneumoniae; RSV, respiratory syncytial virus; ADV, adenovirus; COX, Coxiella burneti; CPn, Chlamydia pneumoniae; FluA, influenza A virus; LPN-I, Legionella pneumophila serogroup I; PIV, parainfluenza virus

\subsection{Distribution of age Groups}

The detection result of the nine respiratory pathogens from different age groups is shown in Table 2 below. The detectable rates of the individual groups were $67.3 \%$, 90.9\%, 92.4\% and $91.4 \%$ respectively. The difference between the groups in the total detectable rate was statis- tically significant $(\mathrm{P}<0.05)$. Except for COX, where the detectable rate of 8 pathogens, i.e. LP, MP, ADV, RSV, FLuB, PIV, ADV, FluA and CPn showed a statistically significant difference $(\mathrm{P}<0.05)$. Of all the pathogens, MP topped all others in the detectable rate for all the age groups (53.5\%, $80.0 \%, 80.2 \%$ and $78.2 \%$ respectively), followed by FluB (33.3\%, 58.3\%, 63.1\% and 63.9\%) and RSV (25.2\%, 37.7\%, 45.3\% 
and $38.6 \%$ ). ADV ranked fourth in the $<1$ group and fifth in all the other groups, while PIV ranked fifth in the $<1$ group and fourth in all the other groups. The remaining pathogens showed limited detectable rate in the groups.

Table 2. Detectable Rate of 9 Respiratory Pathogens by age Group (\%)

\begin{tabular}{|c|c|c|c|c|c|c|c|c|c|c|c|}
\hline & Qty $^{\mathrm{a}}$ & Total & $\mathbf{A D V}^{\mathrm{a}}$ & $\operatorname{cox}^{\mathrm{a}}$ & $\mathrm{CPn}^{\mathrm{a}}$ & FluA $^{a}$ & FluB $^{\mathrm{a}}$ & LPN & $\mathbf{M P}^{\mathrm{a}}$ & PIV $^{\mathrm{a}}$ & $\mathbf{R S V}^{\mathrm{a}}$ \\
\hline$<1$ & 2070 & 1393 & $144(7.0)$ & $13(0.6)$ & $2(0.1)$ & $35(1.7)$ & $689(33.3)$ & $20(1.0)$ & $110(53.5)$ & $60(2.9)$ & $521(25.2)$ \\
\hline$>1,<3$ & 1384 & 1258 & $142(10.3)$ & $9(0.7)$ & $3(0.2)$ & $39(2.8)$ & $807(58.3)$ & $36(2.6)$ & $110(80.0)$ & 193 (13.9) & $522(37.7)$ \\
\hline$>3,<6$ & 697 & 644 & $61(8.8)$ & $4(0.6)$ & $3(0.4)$ & $23(3.3)$ & $440(63.1)$ & $24(3.4)$ & $559(80.2)$ & 139 (19.9) & $316(45.3)$ \\
\hline$>6$ & 399 & 365 & $20(5.0)$ & $2(0.5)$ & $5(1.3)$ & $17(4.3)$ & $255(63.9)$ & $17(4.3)$ & $312(78.2)$ & $65(16.3)$ & $154(38.6)$ \\
\hline
\end{tabular}

a Abbreviations: Qty, quantity; FluB, influenza B virus; MP, mycoplasma pneumoniae; RSV, respiratory syncytial virus; ADV, adenovirus; COX, Coxiella burneti; CPn, Chlamydia pneumoniae; FluA, influenza A virus; LPN-I, Legionella pneumophila serogroup I; PIV, parainfluenza virus

\subsection{Seasonal Effect}

MP is not significantly season dependent and has a high detectable rate in all seasons except for December; FluB has two epidemic peaks, one in May and the other in February; RSV also has two epidemic peaks, one in June and the other in November; ADV has only one epidemic peak in June; PIV has two apparent epidemic peaks, one in June and the other in December; FluA, despite its low detectable rate, attacks typically in May and February; LPN1, whose detectable rate is also low, is mostly found during July and February; COX has a very limited detectable rate and is typically found in July. CPn has a very limited detectable rate throughout the year. (Figures 1 and 2).

Figure 1. The Detectable Rate of FluB, MP, RSV and ADV During Different Months

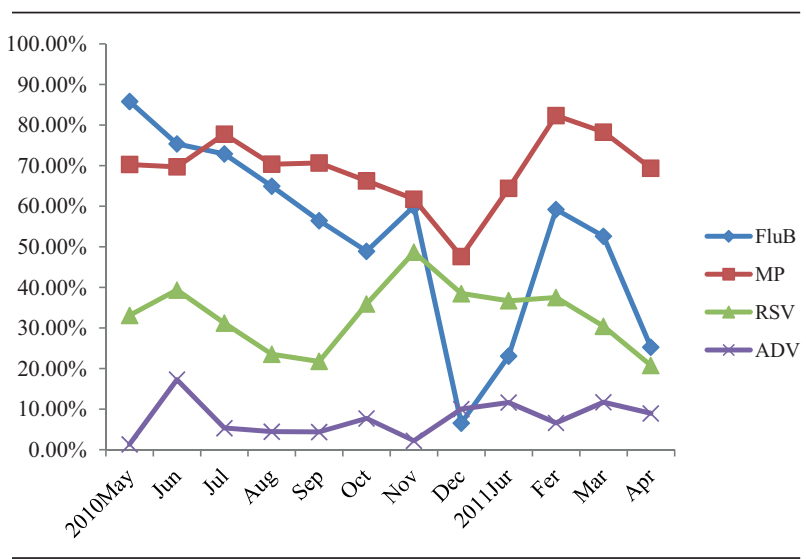

Abbreviations: FluB, influenza B virus; MP, M. pneumoniae; RSV, respiratory syncytial virus; ADV, adenovirus; COX, Coxiellaburneti; $\mathrm{CPn}, \mathrm{C}$. pneumoniae; FluA, influenza A virus; LPN-I, Legionella pneumophila sero group I; PIV, parainfluenza virus

\subsection{Mode of Mixed Infection}

A total of 2439 cases were detected containing two or more pathogens with a detectable rate of $56.7 \%$. Complicated mixed infections were involved. Of the mixed infections containing 2 pathogens, most were of the MP + FluB combination, which totaled 764 (that is $31.3 \%$ of the total mixed infections), followed by FLuB + RSV, which was 221 (9.1\%). Of the mixed infections containing 3 pathogens, most were of the MP + FLuB + RSV combination, which totaled 37 (5.9\%), followed by MP + FluB + RSV + ADV, which included 62 victims (2.5\%); other mixed infections involved limited positive cases and contributed to $24.9 \%$ of cases, as shown in Table 3 below.

Table 3. Mixed Infections of 9 Respiratory Pathogens

\begin{tabular}{lll}
\hline Mode of Mixed Infection & Qty & Percentage, \% \\
\hline MPa + FLuBa & 764 & 31.3 \\
FLuB + RSVa & 221 & 9.1 \\
MP + FLuB + RSV & 547 & 22.4 \\
MP + FLuB + PIV & 95 & 3.9 \\
MP + FLuB + RSV + PIVa & 143 & 5.9 \\
MP + FluB + RSV + ADVa & 62 & 2.5 \\
Other Modes of Mixed Infection & 607 & 24.9 \\
Total & 2439 & 100.0 \\
\hline
\end{tabular}

Figure 2. The Detectable Rate of COX, CPn, FluA, LPN1 and PIV DuringDifferent Months

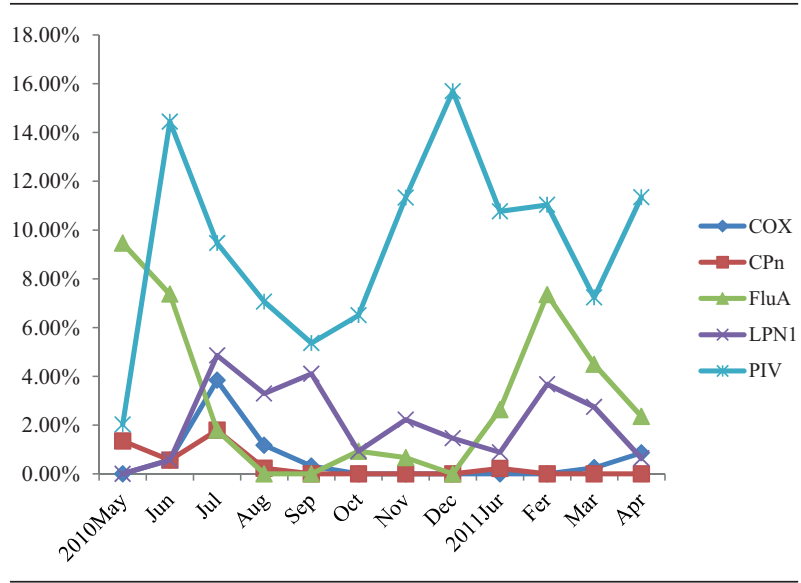

Abbreviations:COX, Coxiellaburneti; CPn, C. pneumoniae; FluA, influenza A virus; LPN-I, Legionella pneumophila sero group I; PIV, parainfluenza virus 


\section{Discussion}

During this study, IgM antibodies of nine commonly seen pathogens in the serum of hospitalized children at the pediatrics department with symptoms of respiratory infections were detected by the FIA method. The result indicates that pathogens causing acute respiratory infections typically include MP, FluB and RSV. Of the 4550 child victims, the total detectable antibody rate was $80.4 \%$, which confirms some previous reports (11-13) but was higher than some others (14-16). This may relate to the varied epidemiology of different pathogens $(17,18)$, physical locations, population susceptibilities and methodologies (19-21). Another reason might be that our study focused on hospitalized children, which resulted in a higher detectable rate than a general screening. For the local area, MP, FluB and RSV are believed to be the primary pathogens leading to ARI, with their infection rates being $69.2 \%, 49.2 \%$ and $34.1 \%$ respectively, followed by PIV, ADV, FluA, LPN1, COX and CP, whose infection rates are 10.3\%, $8.2 \%, 2.6 \%, 2.2 \%, 0.6 \%$ and $0.3 \%$ respectively.

MP is an important pathogen for child respiratory infections, ranking first in our results and higher than Shenzhen and Wenzhou $(22,23)$. This is particularly demonstrated by the 3-6 y group whose detectable rate was as high as $80.2 \%$, and also by the $1-3 y$ group and the $>6$ group, whose detectable rates were $80.0 \%$ and $78.2 \%$ respectively, suggesting that children $>1$ are more susceptible to MP. Besides, FluB is also one of the most commonly seen pathogens for acute child respiratory infection, only second to MP and higher than other countries and the area $(24,25)$. Noticeable difference was also found in the infection degree between different age groups and the 3-6y group proved to have the highest infection rate. The infection rate of respiratory syncytial virus conforms to that reported for Shanghai and part of Guangdong (26, 27) and lower than other countries and the Suzhou area $(28,29)$. Of all the age groups, the 3-6 y group had the highest infection rate.

Of the pathogens studied, MP is not significantly season dependent and maintains a high detectable rate throughout the year except for December, which conforms to other reported conclusions $(28,29)$. FluB, on the other side, typically comes during winter and spring, which confirms other reported conclusions (30, 31); RSV typically comes in summer and winter, also confirming other reported conclusions $(32,33)$; and ADV typically comes in summer, which does not fully agree with previous reports $(34,35)$; PIV typically comes in summer and winter, which is in accordance with previous reports (36, 37); FluA, despite its lower detectable rate, becomes more concentrated during May and February; LPN1, which also shows a low detectable rate, comes mostly during July and February; COX, with a very low detectable rate, comes mostly in July; CPn has a very low detectable rate throughout the year. This can lead us to the conclusion that MP, RSV and COX are noticeably season dependent.
A relatively high rate of mixed infections was revealed from our study, which does not fully agree with other reports $(12,38)$. Of the mixed infections containing two pathogens, the MP+INFB and FLuB + RSV combinations are more frequently found; of the mixed infections containing three pathogens, the MP + FLuB + RSV and MP + FLuB + PIV combinations are more frequently found; of the mixed infections containing four pathogens, the MP $+\mathrm{FLuB}+\mathrm{RSV}+\mathrm{PIV}$ combination is the most frequently found. This might be explained by airway mucosal cell injuries after infections by one pathogen (e.g. MP) that make it easier for other pathogens to attack, or by increased chances for cross infections as a result of the poor health and low immunity of the children, the long course of disease, extended hospitalization and contact with other sick children.

In this respect, appropriate isolation will be necessary for children during their hospitalization to prevent nosocomial infection. So far, a lot of detection methods are available for acute respiratory infectious pathogens. These include isolated culture, pneumonia pathogen specific antibody and antigen detection and PCR. Despite the role it plays in diagnosis, isolated culture of MP proves impractical to be popularized in clinical practice as it does not provide a high detectable rate and requires high skills and long culture cycles. PCR, although sensitive, it is not normally used for routine laboratory detection (particularly in developing countries) due to its high detection cost. Immunofluorescence assay, on the other side, is more acceptable for developing countries as it enables rapid detection of antibodies due to its sensitive and specific properties and provides immediate etiological basis for clinical diagnosis at a much lower cost.

In summary, we conducted a rapid detection for acute child respiratory infections by the IFA method for one year and gained an understanding of the virus etiology for acute child respiratory infections in the local area. While some of the pathogens remain unidentified, this provides an effective tool for etiological diagnosis of child ARI victims. As respiratory pathogen infections are potential causes of severe complications that threaten children's health, rapid detection of respiratory pathogens is very essential for the correct and appropriate treatment of respiratory infections as it enables timely treatment of the victims and prevents complications.

\section{Acknowledgements}

None declared.

\section{Authors' Contribution}

None Declared.

\section{Financial Disclosure}

None declared. 


\section{Funding/Support}

None declared.

\section{References}

1. Williams Brian G, Gouws Eleanor, Boschi-Pinto Cynthia, Bryce Jennifer, Dye Christopher. Estimates of world-wide distribution of child deaths from acute respiratory infections. Lancet Infect Dis. 2002;2(1):25-32.

2. Black Robert E, Cousens Simon, Johnson Hope L, Lawn Joy E, Rudan Igor, Bassani Diego G, et al. Global, regional, and national causes of child mortality in 2008: a systematic analysis. Lancet. 2010;375(9730):1969-1987.

3. Bryce Jennifer, Boschi-Pinto Cynthia, Shibuya Kenji, Black Robert E. WHO estimates of the causes of death in children. Lancet. 2005;365(9465):1147-1152.

4. Weigl JA, Puppe W, Meyer CU, Berner R, Forster J, Schmitt HJ, et al. Ten years' experience with year-round active surveillance of up to 19 respiratory pathogens in children. Eur J Pediatr. 2007;166(9):957-66.

5. Ruuskanen Olli, Lahti Elina, Jennings Lance C, Murdoch David R. Viral pneumonia. Lancet. 2011;377(9773):1264-1275.

6. Kumar S, Wang L, Fan J, Kraft A, Bose ME, Tiwari S, et al. Detection of 11 common viral and bacterial pathogens causing community-acquired pneumonia or sepsis in asymptomatic patients by using a multiplex reverse transcription-PCR assay with manual (enzyme hybridization) or automated (electronic microarray) detection.J Clin Microbiol. 2008;46(9):3063-72.

7. van den Hoogen BG, de Jong JC, Groen J, Kuiken T, de Groot R, Fouchier RA, et al. A newly discovered human pneumovirus isolated from young children with respiratory tract disease. Nat Med. 2001;7(6):719-24

8. Pyrc K, Berkhout B, van der Hoek L. The novel human coronaviruses NL63 and HKU1. JVirol. 2007;81(7):3051-7.

9. Mardy S, Ly S, Heng S, Vong S, Huch C, Nora C, et al. Influenza activity in Cambodia during 2006-2008. BMC Infect Dis. 2009;9:168.

10. Brundage John F. Interactions between influenza and bacterial respiratory pathogens: implications for pandemic preparedness. Lancet Infect Dis. 2006;6(5):303-312.

11. Kim CK, Choi J, Callaway Z, Kim HB, Chung JY, Koh YY, et al. Clinical and epidemiological comparison of human metapneumovirus and respiratory syncytial virus in seoul, Korea, 2003-2008. J Korean Med Sci. 2010;25(3):342-7.

12. Peng D, Zhao D, Liu J, Wang X, Yang K, Xicheng H, et al. Multipathogen infections in hospitalized children with acute respiratory infections. Virol J. 2009;6:155.

13. Tang LF, Wang TL, Tang HF, Chen ZM. Viral pathogens of acute lower respiratory tract infection in China. Indian Pediatr. 2008;45(12):971-5.

14. Sadeghi CD, Aebi C, Gorgievski-Hrisoho M, Muhlemann K, Barbani MT. Twelve years' detection of respiratory viruses by immunofluorescence in hospitalised children: impact of the introduction of a new respiratory picornavirus assay. BMC Infect Dis. 2011;11:41.

15. Do AH, van Doorn HR, Nghiem MN, Bryant JE, Hoang TH, Do QH, et al. Viral etiologies of acute respiratory infections among hospitalized Vietnamese children in Ho Chi Minh City, 2004-2008. PLoS One. 2011;6(3).

16. Fry AM, Chittaganpitch M, Baggett HC, Peret TC, Dare RK, Sawatwong $\mathrm{P}$, et al. The burden of hospitalized lower respiratory tract infection due to respiratory syncytial virus in rural Thailand. PLoS One. 2010;5(11)

17. Razanajatovo NH, Richard V, Hoffmann J, Reynes JM, Razafitrimo GM, Randremanana RV, et al. Viral etiology of influenza-like illnesses in Antananarivo, Madagascar, July 2008 to June 2009. PLoS One. 2011;6(3).

18. Bezerra PG, Britto MC, Correia JB, Duarte Mdo C, Fonceca AM, Rose K, et al. Viral and atypical bacterial detection in acute respiratory infection in children under five years. PLoS One. 2011;6(4).

19. Tregoning JS, Schwarze J. Respiratory viral infections in infants: causes, clinical symptoms, virology, and immunology. Clin Microbiol Rev. 2010;23(1):74-98.

20. Henrickson KJ. Advances in the laboratory diagnosis of viral respiratory disease. Pediatr Infect Dis J. 2004;23(1 Suppl):S6-10.

21. Cilla G, Onate E, Perez-Yarza EG, Montes M, Vicente D, Perez-Trallero E. Viruses in community-acquired pneumonia in children aged less than 3 years old: High rate of viral coinfection. J Med Virol. 2008;80(10):1843-9.

22. Fabbiani M, Terrosi C, Martorelli B, Valentini M, Bernini L, Cellesi C, et al. Epidemiological and clinical study of viral respiratory tract infections in children from Italy. J Med Virol. 2009;81(4):7506.

23. Defilippi A, Silvestri M, Tacchella A, Giacchino R, Melioli G, D Marco E, et al. Epidemiology and clinical features of Mycoplasma pneumoniae infection in children. RespirMed. 2008;102(12):1762-

24. Cabello C, Manjarrez ME, Olvera R, Villalba J, Valle L, Paramo I. Frequency of viruses associated with acute respiratory infections in children younger than five years of age at a locality of Mexico City. Memórias do Instituto Oswaldo Cruz. 2006;101(1):21-24.

25. Bonzel L, Tenenbaum T, Schroten H, Schildgen O, SchweitzerKrantz S, Adams O. Frequent detection of viral coinfection in children hospitalized with acute respiratory tract infection using a real-time polymerase chain reaction. Pediatr Infect Dis J. 2008;27(7):589-94.

26. Yeolekar LR, Damle RG, Kamat AN, Khude MR, Simha V, Pandit AN Respiratory viruses in acute respiratory tract infections in Western India. Indian JPediatr. 2008;75(4):341-5.

27. Nair Harish, Nokes D James, Gessner Bradford D, Dherani Mukesh, Madhi Shabir A, Singleton Rosalyn J, et al. Global burden of acute lower respiratory infections due to respiratory syncytial virus in young children: a systematic review and meta-analysis. Lancet. 2010;375(9725):1545-1555.

28. Noyola DE, Zuviri-Gonzalez A, Castro-Garcia JA, Ochoa-Zavala JR. Impact of respiratory syncytial virus on hospital admissions in children younger than 3 years of age. J Infect. 2007;54(2):180-4.

29. Thavagnanam S, Christie SN, Doherty GM, Coyle PV, Shields MD Heaney LG. Respiratory viral infection in lower airways of asymptomatic children. Acta Paediatr. 2010;99(3):394-8.

30. Wang W, Cavailler P, Ren P, Zhang J, Dong W, Yan H, et al. Molecular monitoring of causative viruses in child acute respiratory infection in endemo-epidemic situations in Shanghai. J Clin Virol. 2010;49(3):211-8.

31. Renois F, Talmud D, Huguenin A, Moutte L, Strady C, Cousson J, et al. Rapid detection of respiratory tract viral infections and coinfections in patients with influenza-like illnesses by use of reverse transcription-PCR DNA microarray systems.J Clin Microbiol. 2010;48(11):3836-42.

32. Maitreyi RS, Broor S, Kabra SK, Ghosh M, Seth P, Dar L, et al. Rapid detection of respiratory viruses by centrifugation enhanced cultures from children with acute lower respiratory tract infections. J Clin Virol. 2000;16(1):41-47.

33. Bharaj P, Sullender WM, Kabra SK, Mani K, Cherian J, Tyagi V, et al. Respiratory viral infections detected by multiplex PCR among pediatric patients with lower respiratory tract infections seen at an urban hospital in Delhi from 2005 to 2007. Virol J. 2009;6:89.

34. Mathisen M, Strand TA, Sharma BN, Chandyo RK, ValentinerBranth P, Basnet S, et al. RNA viruses in community-acquired childhood pneumonia in semi-urban Nepal; a cross-sectional study. BMC Med. 2009;7:35.

35. Kusel MM, de Klerk NH, Holt PG, Kebadze T, Johnston SL, Sly PD. Role of respiratory viruses in acute upper and lower respiratory tract illness in the first year of life: a birth cohort study. Pediatr Infect Dis J. 2006;25(8):680-6.

36. Barbani MT, Gorgievski-Hrisoho M. Rapid detection of respiratory picornaviruses in nasopharyngeal aspirates by immunofluorescence assay. J Clin Virol. 2009;45(3):245-8.

37. Kim SR, Ki CS, Lee NY. Rapid detection and identification of 12 respiratory viruses using a dual priming oligonucleotide systembased multiplex PCR assay. JVirol Methods. 2009;156(1-2):111-6.

38. Fattouh AM, Mansi YA, El-Anany MG, El-Kholy AA, El-Karaksy HM. 
Acute lower respiratory tract infection due to respiratory syncytial virus in a group of Egyptian children under 5 years of age. Ital J Pediatr. 2011;37:14.
Please cite this paper as: Xuan C, Yan L, Zegang W. Rapid Detection of Acute Respiratory Virus and Atypical Bacteria Infections in Children. Jundishapur J Microbiol. 2013;6(5):e6236. DOI: 10.5812/ jjm.6236 